\title{
A FUNÇÃO CATÁRTICA DA FOTOGRAFIA DE SEBASTIÃO SALGADO
}

\section{THE CATHARTIC FUNCTION OF SEBASTIÃO SALGADO'S PHOTOGRAPH}

\author{
Luiz Gonzaga Marchezan
}

UNESP - Universidade Estadual Paulista (FCLAr)

RESUMO: Este artigo compara os diferentes atos fotográficos de Henri Cartier-Bresson e Sebastião Salgado.

PALAVRAS-CHAVE: Fotografia; Luz; Espaço; Tempo.

ABSTRACT: This article compares the different photographic acts of Henri Cartier-Bresson and Sebastião Salgado.

KEYWORDS: Photograph; Light; Space; Time

Houve, no Brasil, quem aproximou as fotografias de Sebastião Salgado das de Cartier-Bresson sem querer ver diferenças. Henri Cartier-Bresson, por sua vez, num depoimento que deu sobre a fotografia do brasileiro, lembrado por Matinas Suzuki enquanto entrevistava Salgado no Programa Roda Viva, qualificou-a como "messiânica", diante do que Sebastião Salgado (1996, p.26-27) ponderou:

Eu acho que não. Acho que não. Mas tem que ver o seguinte: eu sou brasileiro, sou do Vale do Rio Doce, eu senti o mundo de outra forma que Cartier-Bresson sentiu. Cartier-Bresson é de uma grande família francesa, altíssima burguesia. Então, nós nos deslocamos no mundo, mais ou menos no mesmo mundo, no mesmo espaço, mas com visões diferentes. Ele sempre achou que o importante na fotografia era o momento decisivo.

Salgado admira Bresson, um de seus fotógrafos preferidos, como deixou claro pelas palavras seguintes que vieram no curso do depoimento acima, conforme entrevista que concedeu ao Programa Roda Viva, na TV Cultura de São Paulo, em 22-4-96:

Acho que, no meu caso, não é importante só aquele momento onde só a forma está materializada. Você tem que ter a forma, mas tem que ter, também, uma dose muito grande de sentimento. A primeira coisa que acho

\footnotetext{
${ }^{1}$ Conforme SALGADO (1996, p.26).
} 
que tenho que defender do ser humano - da espécie humana - é a dignidade. Acho isso capital na fotografia. Então, talvez seja isso que Cartier-Bresson associe com a parte messiânica. (SALGADO, 1996, p.27)

Convenhamos que o fotógrafo brasileiro e o francês gostem do retrato e que procuram, com esse tipo de linguagem fotográfica, retratar atitudes. Atitudes que, para ambos, como no Dicionário, são posições tomadas pelo corpo: portes, jeitos, posturas.

Admitamos também que haja nas imagens que ambos retratam uma disposição para a observação de rostos e mãos. Evidenciemos, porém, que Cartier-Bresson alterna a fotografia frontal com a de perfil e que Salgado fotografa, preferencialmente, de forma frontal, sempre contraluz. No mesmo Programa Roda Viva citado, o fotógrafo brasileiro comentou:

Cada fotógrafo tem uma estética, só uma, não tem duas. Fotógrafo só fotografa da maneira que ele pode fotografar, não fotografa de outra forma. E eu fotografo com a minha cidadezinha lá do interior de Minas, como eu olhava, eu seguro o que eu fotografo. Porque é uma cidade ${ }^{2}$ que tem um sol fabuloso, um calor imenso. A gente está sempre na sombra. Eu aprendi a ver o mundo em contraluz, porque a gente estava sempre na sombra [...] Então, eu aprendi a ver contraluz, e descobri, muitos anos depois, que eu fotografava contraluz. (SALGADO, 1996, p.8).

$\mathrm{O}$ retrato frontal, contraluz, elimina as sombras do primeiro plano a fim de projetá-las num segundo; enfatiza, assim, o foco central da foto em relação às grandes áreas de sombra da sua periferia; cria, com isso, ao saturar as cores no primeiro plano, profundidade, ambientação, no segundo. Salgado, acima de tudo, quando fotografa contraluz, aproxima o seu processo criativo das condições para a fotografia de campo, em espaço aberto. Bresson, preferencialmente, realiza seus retratos em espaços fechados, encenando-os, atento a uma gama de luzes indiretas (frontal, lateral, semi-lateral, etc).

Bresson, em seus retratos, pautados por seus momentos decisivos, avizinha-se dos seus flagrantes, seus acasos, produto da eloquência do seu discurso fotográfico. Salgado, em seus retratos, fotografa o descaso, momentos em que suas fotos situam-se numa fronteira entre a eloquência e o fato. Para ambos, o ícone não é mais o que representa, dilui-se na foto e sustenta-se como uma figura. Os dois fotógrafos, dessa maneira, não trabalham com a pura emanação do referente. A função da sua fotografia não é a de ratificar o seu referente. A representação sobrepõe-se à apresentação. O momento decisivo de Bresson compõe, invariavelmente, uma ironia (composta por metonímias metaforizadas), em que duas situações se sobrepõem, numa dissonância entre o literal e o figurado. O discurso de Salgado, que também trabalha com metonímias metaforizadas, constrói uma simulação, por meio de uma narrativa voltada para e explicação do seu tema, com a pretensão de informar sobre o seu tema, julgá-lo. Assim, a metonímia desloca a ênfase da parte para o todo e provoca uma interpretação da sua referência: a imagem fotografada por Sebastião Salgado emoldura a parte de um todo que está ausente; provoca uma comparação, uma relação. As partes, lógica e artisticamente, fazem sentido, porém, reverberam quando integradas ao todo ausente. Dessa maneira, somente a totalidade faz sentido, a união entre as partes, a partir do senso de apresentação do ícone ao lado da estratégia de representação da metonímia. Dessa maneira, a

\footnotetext{
${ }^{2}$ Aimorés, MG.
} 
figura fala mais e com o referente. A metáfora metonimizada reúne esses dois campos de acontecimentos: duplica-os, compara-os, conota-os.

A ação de uma narrativa fotográfica é pontual, simula um estado (de acaso ou descaso, como queremos aqui); o estatuto do retrato, mais precisamente, contraria a narratividade, enunciados fotográficos acoplados que simulem descontinuidade dentro de uma mesma situação narrativa; uma ação, enfim, com duração. Um retrato não tem encaixe, contiguidade, pressuposição, outra unidade narrativa, que transforme uma situação primeira em relação à segunda. Um retrato organiza numa cena um acontecimento; não é do seu estatuto combinar esse acontecimento com outro, em sequência e, desse modo, criar uma descontinuidade, ampliar a duração da cena retratada. Os momentos decisivos de Bresson cabem dentro de um único retrato, conforme a foto que dele analisaremos, conforme Anexo A.

A fotografia dilemática de Sebastião Salgado, no caso, não. Foi impossível para o fotógrafo brasileiro, conforme Anexo B, ler, "em Perambu, nos confins do sertão do Ceará", segundo sua legenda, "a dignidade e a pobreza" como "companheiras inseparáveis da população do campo" numa só foto. (SALGADO, 1997, p.138) Diante disso, compôs, de maneira surpreendente, para uma mesma página, um retrato bipartido; mais, combinou, para um rosto dobrado pelo sofrimento, da foto acima da página, as mesmas dobras, agora, abaixo da mesma página e presentes nas duas mãos que cobrem aquele rosto. A intensidade da luz, nessas duas fotos frontais, está voltada para o primeiro plano, saturada, a fim de ressaltar uma descontinuidade em que transparece a organização de um sentido segmentado pela descontinuidade. Nela, uma ruptura, notável: um ator, com dois papéis, o da pobreza e o da dignidade, caros ao fotógrafo, firmados em legenda - coisas que devem ser lidas, conforme definição do Dicionário.

O sentido dessas duas fotografias de Sebastião Salgado, editadas em seu livro Terra, de 1997, evidencia-nos que o fazer humano, como para a semiótica, não se estabelece numa simples relação de comunicação, mas de significação com o mundo e, por isso, o sentido do fazer humano deve ser abordado dentro uma representação espácio-temporal. A fotografia de Sebastião Salgado é um fazer com uma preocupação em registrar imagens de interesse planetário: para o fotógrafo, a imagem é uma linguagem universal, que incorpora as perplexidades que invadem coletividades. A fotografia ${ }^{3}$ é uma operação mecânica apoiada pela química e pela física - uma fixação fotoquímica dos sinais de luz emitidos pelos próprios objetos do mundo. Desse ponto de vista, a sua imagem apresenta-nos, no caso, um campo denotado, referencial, "falado", Ceará. A imagem da fotografia pretendida por Salgado quer representar uma situação num campo conotado, figurado, "falante", e, por isso, ganha uma importância superior à do campo "falado", denotado. O fotógrafo de Terra transcende o factual, registrado por meio de um processo físico-químico de correspondência ponto-a-ponto; prefere a imagem figurada, que constrói por meio de uma aliança entre um ícone e uma metonímia, estratégia comum em sua obra. A foto de Salgado, por meio dessa estratégia, articula uma analogia eficaz, mecanicamente assegurada, com mediações em que cintilam uma descontinuidade, uma ruptura, que expande o sentido da sua mensagem fotográfica além da pura emanação do referente. A metonímia "falante", conotada, da fotografia de Sebastião Salgado consegue uma recepção superior à da fotografia "falada", denotada e, assim, ganha a adesão de partes sugestivas de um planeta preocupadas com os problemas globais, que veem semelhanças entre partes do seu mundo com as partes do mundo fotografadas por Salgado e observam que tais semelhanças remetem para uma identidade nacional ameaçada. A

\footnotetext{
${ }^{3}$ Não analisamos aqui fotografias digitais.
} 
metonímia de Sebastião Salgado desloca a ênfase do referente - mostra uma parte que está no todo e, assim, provoca, por meio de uma estetização do sofrimento, um debate entre conformidades identitárias, com imagens construídas através das funções referencial (solidária com o objeto que representa), poética (ambígua, que configura artisticamente uma situação polêmica) e catártica (porque cognoscitiva, com o objetivo de fotografar um pensamento de indignação sobre a marginalidade a que estão sujeitos os mais diversos grupos sociais do planeta, momento esse em que a fotografia de Sebastião Salgado suplanta fronteiras culturais).

A sequência de fotos de Sebastião Salgado traz-nos, de acordo com o Anexo B, na primeira delas, o rosto sofrido de uma senhora, e, na segunda, esse mesmo rosto, agora, coberto pelas mãos dessa mesma senhora. Assim, rosto e mãos, nestas fotos de Salgado, não transmitem uma idéia de atividade ou força, de ação ou ânimo; mãos marcadas espalmadas sobre um rosto também marcado cobrem, com suas marcas, o mesmo sofrimento latente naquela senhora. Temos, dessa maneira, a partir do que o fotógrafo sanciona por meio da legenda a que já nos referimos, um paralelo entre um rosto sofrido e mãos também vincadas pela dureza do trabalho na terra, com os sulcos da terra árida; um paralelo, enfim, entre a terra com um rosto e mãos de uma senhora trabalhadora dessa mesma terra. Rosto e mãos sofridos versus chão sofrido. Os traços do rosto e das mãos nos traços do chão. A metáfora duplica os campos de imagens da metonímia com o objetivo de enfatizar uma situação e, desse modo, alegoriza. A alegoria é uma metáfora ampliada, estratégia final da fotografia polêmica de Sebastião Salgado.

A fotografia de Sebastião Salgado, no caso, mostra-nos sua intencionalidade; provoca uma ruptura: monta uma sequência, um processo, com imagens que indicam, a partir de uma só personagem, uma intenção em organizar um sentido, por meio de dois papéis, numa segmentação que manifesta uma continuidade de sentido. A sequência de fotos de Sebastião Salgado volta-se para a explicação do seu tema (o que não é da intenção de CartierBresson) e pretende informar sobre o seu tema, julgá-lo. Assim, sobrepõe imagens que provocam uma interpretação da sua referência. Salgado alegoriza: apreende o falado, literal, individual, a fim de fazê-lo falante, figurado, universal. A alegoria expõe um juízo por meio da tradução de campos de imagem e idéias da narrativa que mostra.

Na foto de Cartier-Bresson, Faulkner, seu perfil, seus braços e mãos retesados, e as pernas traseiras esticadas do pequeno cão ao seu lado, de acordo com o Anexo A, também compõem um paralelo, momento em que o instante fotográfico flagra uma idéia de atividade, força, sem intencionalidade; puro acaso. Dessa maneira, o flagrante constitui-se numa ironia, num discurso deslocado, que desloca a ênfase, que desloca de um todo, algumas partes, que relaciona para compará-las com humor, flagrando-as na sua dissonância: um homem, num dado momento, movimenta-se como um pequeno cachorro.

Com a primeira atitude, temos uma sequência de fatos produzida pela poética da emotividade, fundada na subjetividade do destinador para a do destinatário, para a comoção do destinatário; a segunda traz consigo uma poética da conatividade, voltada para o destinatário, para a ação fotográfica. Nesta disposição, a poética da conatividade, por metonímias, flagra o homem numa ação idêntica à do animal; faz-se ambígua, irônica. A poética da emotividade, por sua vez, que também metaforiza suas metonímias, recria, no interior da sua disposição, uma nova referência.

Cartier-Bresson fixou-se na mímese, na coerência interna da sua representação, flagrando uma imagem coerente e pragmaticamente. Salgado tramou, numa sequência, rosto com mãos; uniu mimese à poiési e coagiu o seu objeto metonímico para compor uma nova ordem, ampliando a duração do seu retrato, a fim de metaforizá-lo e construir, de modo 
cognitivo, uma analogia alegórica. Salgado alegoriza: apreende o falado, literal, individual, a fim de fazê-lo falante, figurado, universal. A alegoria expõe um juízo por meio da tradução de campos de imagem e idéias da narrativa: mostra-nos algo legendário, conforme a legenda das fotos:

Em Parambu, nos confins do sertão do Ceará, próximo da serra Grande, a dignidade e a pobreza são companheiras inseparáveis da população do campo. Ali, a luta pela sobrevivência se revela das mais difíceis. E este bicho humano, endurecido, calejado, enfrenta a vida desde o nascimento até a morte com a mesma resolução, batendo-se contra a aridez da terra, as secas prolongadas e a exploração do seu trabalho, consumada dentro de uma estrutura agrária ainda feudal. Ceará, 1983. (SALGADO, 1997, p.138)

A função cognoscitiva da fotografia de Sebastião Salgado na construção da sua alegoria ordena, dá duração às imagens que mostram uma situação vivida, que a legenda do próprio fotógrafo sanciona. A fotografia de Salgado, assim, mostra-nos, poeticamente, um dizer verdadeiro, a fim de nos comover. O flagrante de Cartier-Bresson também ordena sua narrativa, porém, sem duração ou legenda; conta-nos um acaso. Para Bresson as imagens são casuais e captadas pela intuição do fotógrafo. Henri Cartier-Bresson é um flâneur, um observador de costumes, de comportamentos, "no ondulante, no movimento, no fugidio", conforme Baudelaire (1996, p.20). O flâneur, segundo o poeta e ensaísta francês, é alguém a quem cabe "ver o mundo, estar no centro do mundo e permanecer oculto ao mundo", atitudes, para Charles Baudelaire (1996, p.20), de "alguns dos pequenos prazeres desses espíritos independentes, apaixonados, imparciais [...] um eu insaciável do não-eu, que a cada instante o revela e o exprime em imagens mais vivas do que a própria vida, sempre instável e fugidia".

A narrativa fotográfica, na condição de uma categoria abstrata, faz uma mediação entre o homem e o mundo. O enunciado fotográfico, assim, constitui-se como um ponto de vista do homem sobre o mundo. O sujeito da enunciação, o fotógrafo, instala o sujeito do discurso, do enunciado (um não-eu) no tempo e espaço do enunciado. No discurso vê-se ou não a identificação entre os sujeitos do enunciado (do discurso) e da enunciação (da história) diante da presença maior ou menor de subjetividade. Diante disso, no centro das questões, o homem, o homem como a imagem da sua linguagem. A linguagem humana, suas imagens, estão ligadas à imaginação, ao imaginário. A imagem é dialógica. A imagem é uma construção do discurso; faz-se a partir da matéria do mundo; torna-se, assim, um elo entre o que aparenta e representa. A imagem emoldura; é o mundo percebido, "emoldurado" pela percepção, que espacializa e movimenta o mundo. A imagem vê, lê o mundo. A imagem reflete, como vimos, a incompletude do sujeito, momento em que retrata, na maneira como discutimos, por semelhanças, com as metáforas, ou por continuidades, com a metonímia, conforme as narrativas que descrevemos. O imaginário é consistente e especula por meio de figuras e através do discurso. Através dele o mundo humano torna-se expressivo e a linguagem consiste no seu instrumental.

Sebastião Salgado, com sua fotografia, ao procurar defender o ser humano, afasta-se do momento casual e decisivo de Bresson, ou da foto casual de um retrato: ele promove uma interlocução com quem fotografa e com quem lê a sua fotografia. Salgado, ao fotografar, parte de uma situação que os gregos tinham como raiz da filosofia, a do espanto, uma dificuldade, uma falta de saída, uma aporia, que o motiva a fotografar interrogando, afastando do seu horizonte e do seu leitor, falsas opiniões, momento em que se situa como 
CASA, Vol.10 n.2, dezembro de 2012

também esse seu leitor diante de um único pensamento, livre do falso e mergulhado nas contradições sociais. Este é o resultado que Sebastião Salgado espera para a sua fotografia; este é o sentido do catártico na sua ação fotográfica: perguntar, por partes, para todos, por uma saída, uma solução.

\section{REFERÊNCIAS}

BAUDELAIRE, C. Sobre a modernidade. Rio: Editora Paz e Terra, 1996.

CARTIER-BRESSON, H. Tête à tête. Retratos de Henri Cartier-Bresson. São Paulo: Companhia das Letras, 1998.

SALGADO, S. Sebastião Salgado: [entrevista]. Entrevistador: Matinas Suzuki. São Paulo: Fundação Memorial da América Latina / Parlamento Latino-Americano, 1996.

. Terra. São Paulo: Companhia das Letras. 1997 
CASA, Vol.10 n.2, dezembro de 2012

\section{ANEXOS}

ANEXO A: Willian Faulkner, 1947.

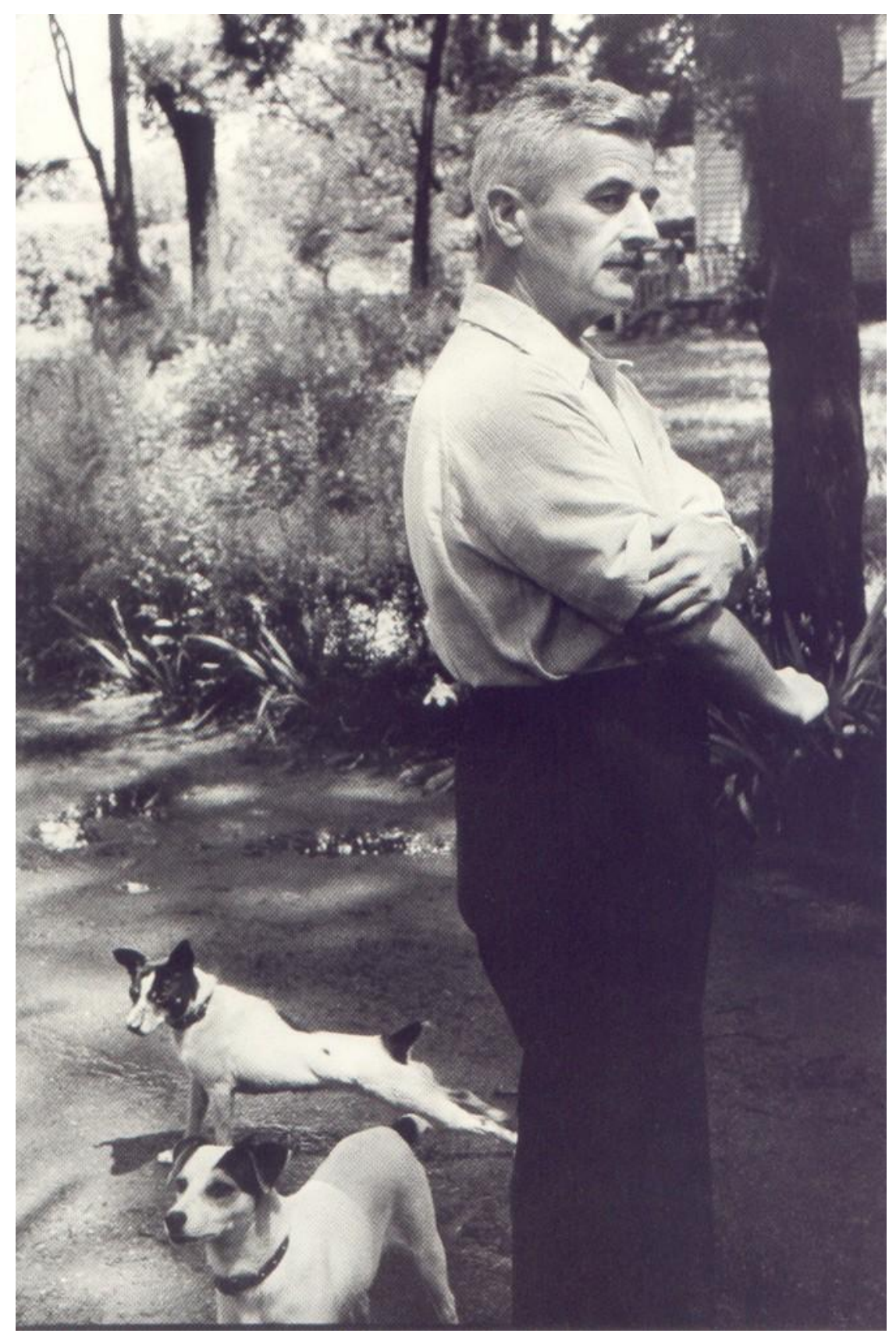

Fonte: CARTIER-BRESSON, H. (1998, p. 10) 
CASA, Vol.10 n.2, dezembro de 2012

\section{Anexo B: Gente da terra.}
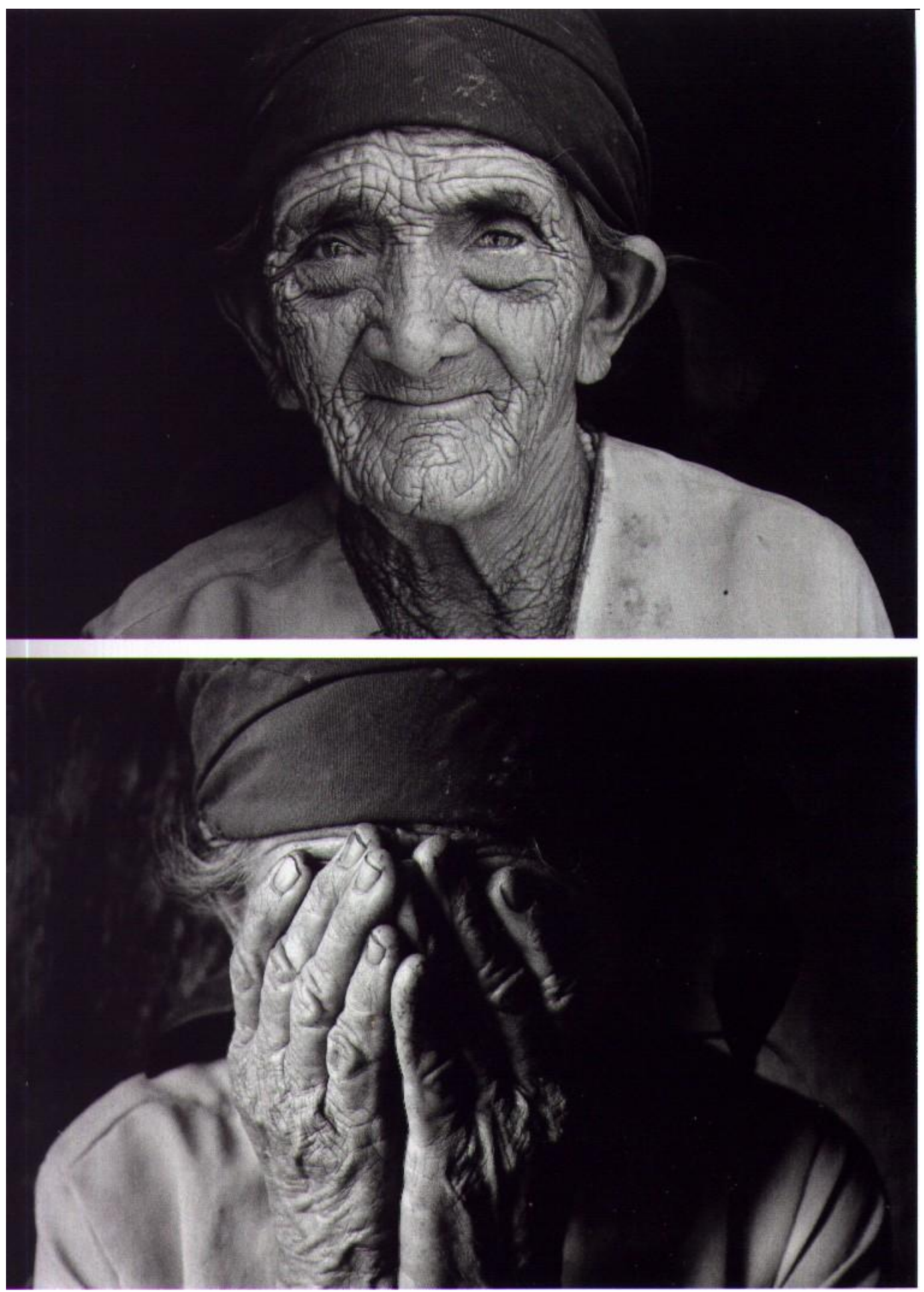

Fonte: SALGADO, S. (1997, p.21)

Recebido em: 10/08/12 Aprovado em: 10/11/12 